\title{
Clinical Outcome of Fine Needle Aspiration Cytology and Washout Thyroglobulin in Suspicious Lymph Nodes in Differentiated Thyroid Carcinoma: Discordant Results in Real-World Practice
}

\author{
Jeongmin Lee ${ }^{1}$, Hye Lim Park ${ }^{2}$ Kwanhoon Jo ${ }^{3}$, Min-Hee Kim, Ja Seong Bae ${ }^{4}$, \\ Sohee Lee ${ }^{5}$, Chan Kwon Jung ${ }^{6}$, So-Lyung Jung ${ }^{7}$ and Dong-Jun Lim ${ }^{8}$ \\ Division of Endocrinology and Metabolism, Department of Internal Medicine, Eunpyeong St. Mary's Hospital, College of Medicine, \\ The Catholic University of Korea ${ }^{1}$, Division of Nuclear Medicine, Department of Radiology, Eunpyeong St. Mary's Hospital, College \\ of Medicine, The Catholic University of Korea ${ }^{2}$, Seoul, Division of Endocrinology and Metabolism, Department of Internal Medicine, \\ Incheon St. Mary's Hospital, College of Medicine, The Catholic University of Korea ${ }^{3}$, Incheon, Department of Surgery, Seoul St. \\ Mary's Hospital, College of Medicine, The Catholic University of Korea4, Department of Surgery, Eunpyeong St. Mary's Hospital, \\ College of Medicine, The Catholic University of Korea ${ }^{5}$, Department of Hospital Pathology, Seoul St. Mary's Hospital, College \\ of Medicine, The Catholic University of Korea ${ }^{6}$, Department of Radiology, Seoul St. Mary's Hospital, College of Medicine, The \\ Catholic University of Korea', Division of Endocrinology and Metabolism, Department of Internal Medicine, Seoul St. Mary's \\ Hospital, College of Medicine, The Catholic University of Korea ${ }^{8}$, Seoul, Korea
}

Background and Objectives: Fine needle aspiration cytology (FNAC) combined with washout thyroglobulin (Tg) measurement is the gold standard for the evaluation of metastatic lymph nodes (LNs) in thyroid cancer. However, few studies have assessed the clinical outcomes of discordant results between FNAC and washout Tg based on surgery status and follow-up imaging in real-world practice. Materials and Methods: A total of 707 LNs in 512 patients who underwent FNAC and washout Tg measurements from 2015 to 2017 were analyzed. The final LN outcomes were confirmed through postoperative histology, or through metastatic FNAC findings combined with high washout Tg level, follow-up imaging studies, or repeat FNA, if LNs were not dissected. Results: The cut-off values of washout Tg for indicating LN metastasis in preoperative and postoperative $L$ Ls were $9.6 \mathrm{ng} / \mathrm{mL}$ and $2.1 \mathrm{ng} / \mathrm{mL}$. The diagnostic accuracy was improved by applying washout Tg according to surgery status and the results of discordant rate was reduced, Discordant between results of FNAC with washout Tg and final outcome were $9.2 \%(27 / 295)$ of preoperative LNs and 8.7\% (36/412) of postoperative LNs. Due to inconclusive results, unnecessary neck dissection can occur in 13.9\% (36/259 dissected cases). Conclusion: To improve diagnostic accuracy, cut-off values of washout Tg should be applied depending on surgery status. New biomarkers in washout fluid is necessary to resolve discordant findings.

Key Words: Thyroid neoplasms, Lymph nodes, Biopsy, Fine-needle, Thyroglobulin, Washout protein

Received January 12, 2021 / Accepted February 2, 2021

Correspondence: Dong-Jun Lim, MD, PhD, Division of Endocrinology and Metabolism, Department of Internal Medicine, Seoul St. Mary's Hospital, College of Medicine, The Catholic University of Korea, 505 Banpo-dong, Seocho-gu, Seoul 06591, Korea Tel: 82-2-2258-6009, Fax: 82-2-599-3589, E-mail: 1dj6026@catholic.ac.kr 


\section{Introduction}

The incidence of thyroid cancer has increased in recent decades. ${ }^{1)}$ Cervical lymph node (LN) metastases in differentiated thyroid carcinoma (DTC) are common. The reported incidence of metastatic LNs is $20-46 \%$ at the initial diagnosis of DTC and local recurrences is reported $5-20 \%$ of cases during surveillance after the initial treatment. ${ }^{2)}$ Although DTC is considered as a cancer with a low mortality rate, ${ }^{3)}$ long-term follow-up studies of DTC patients with LN metastasis showed poor prognosis associated with low survival and high recurrence rates. ${ }^{4,5)}$ Ultrasonography (US) and US-guided fine needle aspiration cytology (FNAC) have been the gold standard modality for the diagnosis of LN metastases before surgery or during cancer surveillance. ${ }^{6}$ However, the results of FNAC can be inadequate in small LNs and are limited by false negative findings in cystic metastatic LNs. ${ }^{7)}$

The direct measurement of thyroglobulin $(\mathrm{Tg})$ in FNA washout fluid (washout Tg) has been proposed to improve the diagnostic outcomes of FNAC. ${ }^{6,8,9)} \mathrm{Tg}$ is a $660 \mathrm{kD}$ glycoprotein which is produced only by the thyroid follicular cells thus, its detection in nonthyroidal tissue could be evidence of persistent or recurrent disease after complete surgery and/or radioiodine therapy. ${ }^{10)}$ Current clinical practice guidelines for thyroid cancer already incorporate washout $\mathrm{Tg}$ as an essential additive to FNAC in suspicious $\mathrm{LNs}^{.1{ }^{11-13)}}$ However, washout Tg levels could be detected at high concentration before surgery due to the presence of a normal thyroid, leading to false positive results. In the case of lobectomy, contralateral lobe might affect the false positivity rate. Serum $\mathrm{Tg}$ antibodies (Ab) could also interfere with washout $\mathrm{Tg}^{14,15)}$ The accuracy of washout Tg and FNAC of LNs has been evaluated in selected patients with total thyroidectomy or near total thyroidectomy. Few studies have assessed discordant results in a wide range of clinical conditions from real-world practice.

This study aimed to 1) evaluate the diagnostic performance of FNAC combined with washout Tg by applying different cut-off $\mathrm{Tg}$ values to preoperative and postoperative LNs and 2) assess the clinical outcome of discrepant results between FNAC combined with washout $\mathrm{Tg}$ and final histopathologic diagnosis.

\section{Materials and Methods}

\section{Subject}

From January 2015 to December 2017, 566 patients with 774 LNs suspicious for metastatic diseases un-

\begin{tabular}{|c|c|c|c|c|c|c|c|}
\hline \multicolumn{8}{|c|}{707 LNs (512 patients) evaluated with FNAC and washout Tg for evaluation of suspicious LNs } \\
\hline \multicolumn{4}{|c|}{ Preoperative LNs $(n=295)$} & \multicolumn{4}{|c|}{ Postopeative LNs $(n=412)$} \\
\hline \multicolumn{2}{|c|}{$\mathrm{FNAC}+(\mathrm{n}=88)$} & \multicolumn{2}{|c|}{ FNAC- $(n=207)$} & \multicolumn{2}{|c|}{ FNAC $+(n=119)$} & \multicolumn{2}{|c|}{$F N A C-(n=293)$} \\
\hline $\begin{array}{l}\text { Washout Tg+ } \\
\quad(n=78)\end{array}$ & $\begin{array}{l}\text { Washout Tg- } \\
\quad(n=10)\end{array}$ & $\begin{array}{l}\text { Washout Tg+ } \\
\quad(n=24)\end{array}$ & $\begin{array}{l}\text { Washout Tg- } \\
\quad(n=183)\end{array}$ & $\begin{array}{l}\text { Washout Tg+ } \\
\quad(n=100)\end{array}$ & $\begin{array}{l}\text { Washout Tg- } \\
\quad(n=19)\end{array}$ & $\begin{array}{l}\text { Washout Tg+ } \\
\quad(n=36)\end{array}$ & $\begin{array}{l}\text { Washout Tg- } \\
\quad(n=257)\end{array}$ \\
\hline $\begin{array}{l}\text { LNs dissection } \\
(n=78)\end{array}$ & $\begin{array}{l}\text { LNs dissection } \\
(n=21) \\
\text { No dissection } \\
(n=3)\end{array}$ & $\begin{array}{l}\text { LNs dissection } \\
(n=21) \\
\text { No dissection } \\
(n=3)\end{array}$ & $\begin{array}{l}\text { LNs dissection } \\
(n=23) \\
\text { No dissection } \\
(n=160)\end{array}$ & $\begin{array}{l}\text { LNs dissection } \\
(n=72) \\
\text { No dissection } \\
(n=7) \\
\text { RAI }(n=18) \\
\text { TKI }(n=3)\end{array}$ & $\begin{array}{l}\text { LNs dissection } \\
(n=11) \\
\text { No dissection } \\
(n=3) \\
\text { RAI }(n=3) \\
\text { Repeat FNAC } \\
(n=2)\end{array}$ & $\begin{array}{l}\text { LNs dissection } \\
(n=25) \\
\text { No dissection } \\
(n=5) \\
\text { Repeat FNAC } \\
(n=6)\end{array}$ & $\begin{array}{l}\text { LNs dissection } \\
(n=19) \\
\text { No dissection } \\
(n=238)\end{array}$ \\
\hline Final diagnosis & Final diagnosis & Final diagnosis & Final diagnosis & Final diagnosis & Final diagnosis & Final diagnosis & Final diagnosis \\
\hline $\begin{array}{l}\text { Metastatic } \\
(n=74)\end{array}$ & $\begin{array}{l}\text { Metastatic } \\
(\mathrm{n}=7)\end{array}$ & $\begin{array}{l}\text { Metastatic } \\
(n=7)\end{array}$ & $\begin{array}{l}\text { Metastatic } \\
(n=3)\end{array}$ & $\begin{array}{l}\text { Metastatic } \\
(n=97)\end{array}$ & $\begin{array}{c}\text { Metastatic } \\
(n=15)\end{array}$ & $\begin{array}{l}\text { Metastatic } \\
(n=9)\end{array}$ & $\begin{array}{l}\text { Metastatic } \\
(n=2)\end{array}$ \\
\hline Benign $(n=4)$ & Benign $(n=3)$ & Benign $(n=17)$ & Benign $(n=180)$ & Benign $(n=3)$ & Benign $(n=4)$ & Benign $(n=27)$ & Benign $(n=255)$ \\
\hline
\end{tabular}

Fig. 1. Final diagnosis of all LNs and of the results of FNAC and washout Tg. 
derwent US-guided FNAC and washout Tg measurements at initial diagnosis of thyroid cancer prior to thyroidectomy or during cancer surveillance after thyroidectomy and/or radioiodine ablation at a tertiary referral hospital (Fig. 1). The exclusion criteria were as follows: 1) LNs from primary lesions other than DTC such as anaplastic thyroid carcinoma, medullary thyroid carcinoma, follicular adenoma, and parathyroid adenoma (26 LNs in 19 patients); 2) metastatic LN from malignancy other than thyroid cancer (one LN in one patient; adenocarcinoma from lung metastasis); 3) LNs without serum $\mathrm{Tg}$ and $\mathrm{TgAb}$ at the time of FNAC and washout Tg measurement (nine LNs in eight patients); 4) LNs without follow-up at our institution after the first FNAC and washout Tg measurement (29 LNs in 24 patients); and 5) LNs without any decision after FNAC and washout Tg measurement, no LNs dissection or no imaging follow-up such as thyroid US, neck computed tomography (CT), magnetic resonance imaging (MRI), and positron emission tomography (PET)-CT (two LNs in two patients) during the study periods. Finally, the remaining $707 \mathrm{LNs}$ in 512 patients were evaluated in this study. This study complied with the ethical standards of the Declaration of Helsinki and was approved by the Catholic University of Korea, Catholic Medical Center, Seoul St. Mary's Hospital Institutional Review Board (No. KC17TESI0328). The requirement for informed consent explaining the study purpose and procedures was waived due to the retrospective design of this study.

\section{US-Guided FNAC of Suspicious LNs and Washout Tg Measurement}

US-guided FNAC of suspicious LNs was performed by one of several experienced radiologists. Thyroid and neck US was performed with an HDI 3000 scanner (Advanced Technology Laboratories, Bothell, WA, USA) and an HDI 5000 diagnostic sonography system (Philips Medical Systems, Bothell, WA, USA) with a CL10-5 MHz compact linear array transducer. The criteria and technique for FNAC of suspicious LNs were based on the consensus statement of the Korean Society of Thyroid Radiology. ${ }^{16)}$ Suspicious LNs with cystic change, calcification, hyperechogenicity, abnor- mal vascularity, and loss of central hilar echogenicity on thyroid and neck US received FNAC. After aspiration, the samples were immediately smeared on slides, fixed in $95 \%$ ethanol, and processed by both hematoxylin and eosin and Papanicolaou stains. ${ }^{17)}$ As described in a previous study, ${ }^{15)}$ the same needle and syringe were rinsed with $2 \mathrm{~mL}$ of normal saline, and the washout fluid was submitted for washout $\mathrm{Tg}$ measurement.

\section{Biochemical Analysis: $\mathrm{Tg}$ and $\mathrm{TgAb}$}

Serum $\mathrm{Tg}$ and washout $\mathrm{Tg}$ levels were measured using a monoclonal antibody immunoradiometric assay (Cisbio Bioassays, Codolet, France). The analytical sensitivity, which indicates the lowest detectable concentration with a probability of $95 \%$, was $0.2 \mathrm{ng} / \mathrm{mL}$. The functional sensitivity at which the efficiency variation was equal to $20 \%$ was $0.7 \mathrm{ng} / \mathrm{mL}$. Serum $\mathrm{TgAb}$ levels were measured using a competitive radioimmunoassay kit (ZenTech, Angleur, Belgium) with a functional sensitivity of $<15 \mathrm{IU} / \mathrm{mL}$. The washout $\mathrm{Tg}$ was normalized with dividing by serum $\mathrm{Tg}$ (washout $\mathrm{Tg} /$ serum $\mathrm{Tg}$ ratio).

\section{FNAC Results and Final LN Diagnosis}

The interpretation of FNAC was performed by experienced pathologists who specialized in thyroid cytology. The FNAC results were classified into two groups; 1) metastatic LNs with the presence of highly suspicious atypical cells, or with cytological feature of DTC and 2) benign LNs which were documented as negative for malignancy, reactive hyperplasia, or other benign lymphadenopathies and non-diagnostic including inadequate results due to the absence of cells and the presence of blood only. ${ }^{18)}$

Generally, the final LN diagnosis was confirmed by postoperative histopathologic results. Metastatic LNs were defined as those with postoperative metastasis of histology in the same compartment that was previously noted in FNAC. ${ }^{19)}$ If patients did not undergo LNs dissection, metastatic LNs were defined based on metastatic FNAC results combined with high washout Tg level and lesions that were revealed by imaging studies such as thyroid US, neck CT, PET/CT, or MRI. 
Otherwise, repeat FNAC results showing metastatic cancer cells were included as final metastatic LNs. Benign LNs were confirmed by benign histology after postoperative review. If the target LNs were not dissected and follow-up imaging showed decreased size or no interval change in size during a follow-up of at least two years, the final LNs were considered to be benign. ${ }^{20)}$ If repeat FNAC results revealed benign $L N s$, the final LNs were also defined as benign LNs.

\section{Statistical Analysis}

All statistical analyses were conducted using SPSS software, version 14 (Chicago, IL, USA). Continuous variables with normal distribution were expressed as means and standard deviation. Variables with nonnormal distributions were presented as medians (interquartile range). Comparisons of the basic clinical characteristics between benign and metastatic LNs were performed by independent t-tests for continuous variables and by $\chi^{2}$ or Fisher exact tests for categorical variables in preoperative LNs and postoperative LNs, respectively. A receiver operating characteristic
(ROC) curve analysis was used to confirm the cut-off levels of washout $\mathrm{Tg}$ in our data. The diagnostic performances of FNAC and washout Tg were evaluated with respect to sensitivity, specificity, positive predictive value (PPV), negative predictive value (NPV), and diagnostic accuracy. McNemar's test was used for statistical comparison of their diagnostic performances. All $p$ values $<0.05$ were considered significant, and two-sided tests were used.

\section{Results}

\section{Clinical Characteristic of Patients and LNs in Metastatic and Benign LNs according to Final LNs Diagnosis}

Female gender was significantly more prevalent in both metastatic and benign $L N s(p=0.020)$. There was no significant difference in age between patients with metastatic LNs and those with benign LNs (mean age 47.6 vs. 47.3 years, $p=0.771$ ).

According to the final LN diagnosis, 214 of 707

Table 1. Clinical characteristics of 707 lymph nodes $(L N s)$ and 512 patients according to final LNs diagnosis

\begin{tabular}{|c|c|c|c|}
\hline Characteristics & Metastatic LNs & Benign LNs & $\mathrm{p}$ value \\
\hline \multicolumn{4}{|l|}{ Patients $(n=512)$} \\
\hline Gender male/female (\%) & $55 / 83(39.9 / 60.1)$ & $107 / 267(28.6 / 71.4)$ & 0.020 \\
\hline Age (years) & $47.6 \pm 16.7$ & $47.3 \pm 14.3$ & 0.771 \\
\hline LNs (total=707), (n, \%) & 214/707 (30.3) & 493/707 (69.7) & \\
\hline Time of FNAC and washout $\mathrm{Tg}$ & & & 0.777 \\
\hline Preoperative LNs (n/total, \%) & $91 / 214(42.5)$ & 204/493 (41.4) & \\
\hline Postoperative LNs (n/total, \%) & $123 / 214(57.5)$ & $289 / 493(58.6)$ & \\
\hline US finding* & & & 0.000 \\
\hline Suspicious (n/total, \%) & $122 / 214(57.0)$ & $80 / 493(16.2)$ & \\
\hline Intermediate (n/total, \%) & $73 / 214(34.1)$ & $299 / 493(60.7)$ & \\
\hline Benign (n/total, \%) & $19 / 214(8.9)$ & $114 / 493(23.1)$ & \\
\hline Serum $\operatorname{Tg}(\mathrm{ng} / \mathrm{mL})$ & $27.1 \pm 76.6(0.0-868.2)$ & $22.5 \pm 91.2(0.0-805.7)$ & 0.516 \\
\hline Serum $\operatorname{TgAb}(\mathrm{IU} / \mathrm{mL})$ & $73.5 \pm 249.5(0.1-1896.7)$ & $68.1 \pm 164.6(0.1-9480.1)$ & 0.873 \\
\hline Washout Tg (ng/mL) & $523.4 \pm 385.5(0.0-1251.7)$ & $31.4 \pm 140.9(0.0-1074.0)$ & 0.000 \\
\hline Washout $\mathrm{Tg} /$ serum $\mathrm{Tg}$ ratio & $933.3 \pm 3185.9(0.0-29802.3)$ & $377.3 \pm 5247.9(0.0-11277.3)$ & 0.084 \\
\hline $\begin{array}{l}\text { Discordant results between FNAC } \\
\text { and washout } \operatorname{Tg}(n, \%)\end{array}$ & $42(19.6)$ & $64(13.0)$ & 0.000 \\
\hline
\end{tabular}

Data are expressed as mean \pm standard deviation or median (range) or number including percentage.

FNAC: fine needle aspiration cytology, Tg: thyroglobulin, $\mathrm{TgAb}$ : thyroglobulin antibody, US: ultrasonography *US finding.

Suspicious; micro/macrocalcification, hyperechogenicity, cystic change, and abnormal vascularity. Intermediate; loss of central hilar echo and absence of central hilar vascularity.

Benign; central hilar echo, central hilar vascularity. 
(30.3\%) LN were metastatic; the remaining 493 (69.7\%) were confirmed as benign LNs. Among 214 metastatic LNs, 91 (42.5\%) were evaluated before thyroidectomy with or without LNs dissection and 123 (57.5\%) were postoperative LNs. 204 of 493 (41.4\%) benign LNs were preoperative and 289 (58.6\%) were postoperative. There were significant differences between metastatic and benign LNs in US findings ( $p=$ 0.000). Metastatic LNs showed more suspicious feature than benign LN in US findings. Washout Tg was higher in metastatic LNs with significance (523.4 \pm 385.5 vs. $31.4 \pm 140.9 \mathrm{ng} / \mathrm{mL}, \mathrm{p}=0.000$ ). Normalized washout $\mathrm{Tg}$ with serum $\mathrm{Tg}$ (washout $\mathrm{Tg} /$ serum $\mathrm{Tg}$ ratio) was higher in metastatic $L N$ than in benign $L N$. However, there was no significance $(p=0.084)$. The difference of serum $\mathrm{Tg}$ and serum $\mathrm{TgAb}$ levels were not significant. Discordant rates between FNAC and washout $\mathrm{Tg}$ were higher in metastatic LNs than in benign LNs (19.6\% vs. $13.0 \%, p=0.000$ ) (Table 1).

Table 2 summarizes the clinical characteristics of LNs according to surgery status (preoperative vs. postoperative). Serum $\mathrm{Tg}$ and serum $\mathrm{TgAb}$ levels were higher in preoperative LNs than those in postoperative
LNs ( $p=0.002$ and $p=0.008)$. The rate of discordant results between FNAC and washout $\mathrm{Tg}$ was higher in metastatic LNs than that in benign LNs in both preoperative and postoperative LNs. Overall, the discordant results between FNAC and washout Tg did not differ in preoperative and postoperative LNs (15.3 vs. $14.8 \%, p=0.321)$.

\section{Cut-off Values for Washout $\mathrm{Tg}$ in All LNs, Preoperative LNs, and Postoperative LNs}

In the present study, the diagnostic performance of washout $\mathrm{Tg}$ was determined using an optimal cut-off value of $2.9 \mathrm{ng} / \mathrm{mL}$ in all LNs (area under the receiver operating characteristic curve [AUC] 0.919 , sensitivity $89.3 \%$, and specificity $88.0 \%$, 95\% confidence interval [CI] 0.892-0.945) and the washout $\mathrm{Tg} /$ serum $\mathrm{Tg}$ ratio was 3.0 (AUC 0.873 , sensitivity $82.2 \%$, and specificity $83.8 \%, 95 \% \mathrm{Cl} 0.842-0.904)$. The cut-off value of preoperative washout $\mathrm{Tg}$ was $9.6 \mathrm{ng} / \mathrm{mL}$ (AUC 0.943, sensitivity $89.0 \%$, and specificity $91.7 \%, 95 \% \mathrm{Cl}$ $0.911-0.975)$ and that of postoperative washout $\mathrm{Tg}$ was $2.1 \mathrm{ng} / \mathrm{mL}$ (AUC 0.902, sensitivity $80 \%$, and specificity $87.8 \%, 95 \% \mathrm{Cl} 0.863-0.942)$. The washout

Table 2. Clinical characteristics of 707 lymph nodes (LNs) according surgery status and final outcome

\begin{tabular}{|c|c|c|c|c|c|}
\hline \multirow{2}{*}{ Characteristics } & \multicolumn{2}{|c|}{ Preoperative LNs $(n=295)$} & \multicolumn{2}{|c|}{ Postoperative LNs $(n=412)$} & \multirow{2}{*}{$p$ value } \\
\hline & Metastatic & Benign & Metastatic & Benign & \\
\hline LNs $(n, \%)$ & $91(30.8)$ & $204(69.2)$ & $123(29.9)$ & $289(70.1)$ & \\
\hline US finding* & & & & & 0.572 \\
\hline Suspicious (n, \%) & $59(64.8)$ & $31(15.1)$ & $63(51.2)$ & $49(17.0)$ & \\
\hline Intermediate (n, \%) & $25(27.5)$ & $124(60.8)$ & $48(39.0)$ & $175(60.6)$ & \\
\hline Benign $(n, \%)$ & $7(7.7)$ & $49(24.1)$ & $12(9.8)$ & $65(22.4)$ & \\
\hline Serum $\operatorname{Tg}(\mathrm{ng} / \mathrm{mL})$ & $\begin{array}{l}35.8 \pm 66.5 \\
(0.1-461.7)\end{array}$ & $\begin{array}{l}37.0 \pm 100.1 \\
(0.0-753.5)\end{array}$ & $\begin{array}{l}20.6 \pm 83.0 \\
(0.0-868.2)\end{array}$ & $\begin{array}{l}12.1 \pm 83.0 \\
(0.0-805.7)\end{array}$ & 0.002 \\
\hline Serum $\operatorname{TgAb}(I \mathrm{U} / \mathrm{mL})$ & $\begin{array}{l}91.8 \pm 170.4 \\
(3.4-750.6)\end{array}$ & $\begin{array}{l}111.4 \pm 674.8 \\
(0.1-6480.7)\end{array}$ & $\begin{array}{l}59.6 \pm 295.7 \\
(0.1-1896.7)\end{array}$ & $\begin{array}{l}37.4 \pm 200.5 \\
(0.1-2826.6)\end{array}$ & 0.008 \\
\hline Washout Tg (ng/mL) & $\begin{array}{c}574.7 \pm 366.1 \\
(0.0-1251.7)\end{array}$ & $\begin{array}{r}26.4 \pm 122.6 \\
(0.0-1002.4)\end{array}$ & $\begin{array}{r}485.5 \pm 396.4 \\
(0.0-1248.5)\end{array}$ & $\begin{array}{l}35.0 \pm 152.6 \\
(0.0-1074.0)\end{array}$ & 0.088 \\
\hline Washout $\mathrm{Tg} /$ serum $\mathrm{Tg}$ ratio & $\begin{array}{l}138.8 \pm 1366.5 \\
(0.0-14307.3)\end{array}$ & $\begin{array}{l}194.6 \pm 568.9 \\
(0.0-4309.6)\end{array}$ & $\begin{array}{r}1479.8 \pm 4095.5 \\
(0.0-29802.3)\end{array}$ & $\begin{array}{l}545.6 \pm 6757.6 \\
(0.0-11277.3)\end{array}$ & 0.001 \\
\hline $\begin{array}{l}\text { Discordant results between } \\
\text { FNAC and washout } \operatorname{Tg}(n, \%)\end{array}$ & $16(17.6)$ & $29(9.8)$ & $26(21.1)$ & $35(12.1)$ & 0.321 \\
\hline
\end{tabular}

Data are expressed as median (range) or number including percentage.

FNAC: fine needle aspiration cytology, Tg: thyroglobulin, $\mathrm{TgAb}$ : thyroglobulin antibody, US: ultrasonography *US finding.

Suspicious; micro/macrocalcification, hyperechogenicity, cystic change, and abnormal vascularity. Intermediate; loss of central hilar echo and absence of central hilar vascularity.

Benign; central hilar echo, central hilar vascularity. 
$\mathrm{Tg} /$ serum $\mathrm{Tg}$ ratio for preoperative and postoperative status was 7.0 (AUC 0.919 sensitivity $85.7 \%$, and specificity $89.7 \%, 95 \% \mathrm{Cl} 0.886-0.953$ ), and 2.9 (AUC 0.845 sensitivity $82.1 \%$, and specificity $83.7 \%, 95 \% \mathrm{Cl}$ 0.796-0.893). When applying the cut-off value for washout $\mathrm{Tg}(2.9 \mathrm{ng} / \mathrm{mL})$ regardless of surgery status, the sensitivity, specificity, PPV, NPV, and accuracy of FNAC combined washout Tg were lower than those for the cut-off values according to surgery status (9.6 $\mathrm{ng} / \mathrm{mL}$ in preoperative $\mathrm{LNs}$ and $2.1 \mathrm{ng} / \mathrm{mL}$ in postoperative LNs, respectively) (Table 3). The discordant results between FNAC combined washout $\mathrm{Tg}$ and final diagnosis were reduced from $45(15.3 \%)$ to $34(11.5 \%)$ LNs in 295 preoperative LNs after applying the cut-off for washout $\mathrm{Tg}$ of $9.6 \mathrm{ng} / \mathrm{mL}$. In postoperative LNs, the discordant rate decreased by $1.5 \%$, from 61 of 412 LNs (14.8\%) to 55 of 412 LNs (13.3\%) after applying the cut-off value of $2.1 \mathrm{ng} / \mathrm{mL}$.

\section{Final Diagnosis of All LNs and of the Results of FNAC with Washout $\mathrm{Tg}$}

We analyzed discordant results in FNAC combined with washout $\mathrm{Tg}$ and final diagnosis and decision making. Fig. 1 demonstrated the final diagnosis of all LNs with different cut-off values of washout Tg according surgery status. In preoperative LNs (cut-off of washout $\mathrm{Tg} ; 9.6 \mathrm{ng} / \mathrm{ml}$ ), FNAC with washout $\mathrm{Tg}$ showed concordant in 78 out of 88 (88.6\%) metastatic LNs (FNAC+washout $\mathrm{Tg}+$; metastatic cytology and high titer of washout $\mathrm{Tg}$ ). All these FNAC+washout $\mathrm{Tg}+78 \mathrm{LNs}$ were dissected with thyroidectomy. 74 of 78 dissected LNs were metastatic LNs based on result of postoperative histopathology. Four of 78 $\mathrm{FNAC}+$ washout $\mathrm{Tg}+\mathrm{LNs}$ were revealed as benign
LNs in histopathologic results of same compartment LNs. These four benign LN showed cytology of atypia of undetermined significance (AUS) and metastatic PTC prior to thyroidectomy. 10 LNs with discordant results (FNAC+washout $\mathrm{Tg}^{-}$) were dissected with thyroidectomy. Three of 10 dissected LNs were proven as benign LNs from histopathology.

FNAC with washout Tg showed consistent results in 183 of 207 (88.4\%) benign LNs by FNAC results (FNAC - washout $\mathrm{Tg}-$; benign cytology and low titer of washout Tg). Discordant result (FNAC-washout $\mathrm{Tg}+$ ) were found in 24 of $207 \mathrm{LNs}$ prior to thyroidectomy. Twenty-one of these 24 LN were dissected, of which seven were proven as metastatic LNs. Four of these seven metastatic LNs presented cystic change on thyroid US and results of FNAC were cystic fluid only in two LNs and blood only in two LNs. The remaining three LNs were reported as benign but suspiciously metastatic in FNAC samples. 23 of 183 LNs with FNAC-washout $\mathrm{Tg}$-were resected with thyroidectomy. Final diagnoses in 3 LNs with FNACwashout $\mathrm{Tg}-$ were metastatic LNs. Among these 3 LNs two LNs had nondiagnostic cytology due to insufficient cellularity in FNAC with macrocalcification and one LN showed only blood in FNAC.

\section{Final Diagnosis of Postoperative LNs and of the Results of FNAC with Washout Tg (Fig. 1)}

Among postoperative LNs, FNAC with washout Tg showed concordant results (FNAC+ washout $\mathrm{Tg}+$ ) in 100 of $119(84.0 \%)$ metastatic LNs. Three of the 100 LNs were proven to be benign LNs in same compartment neck. Among the 19 (of 119) with metastatic LNs by FNAC and low washout Tg levels (FNAC+

Table 3. Cut-off values of FNAC with washout Tg measurement and diagnostic performance according to surgery status

\begin{tabular}{lccccccc}
\hline LNs & $\begin{array}{c}\text { Cut-off } \\
\text { value } \\
(\mathrm{ng} / \mathrm{mL})\end{array}$ & $\begin{array}{c}\text { Discordant } \\
\text { results } \\
(\%)\end{array}$ & $\begin{array}{c}\text { Sensitivity } \\
(\%)\end{array}$ & $\begin{array}{c}\text { Specificity } \\
(\%)\end{array}$ & $\begin{array}{c}\text { PPV } \\
(\%)\end{array}$ & $\begin{array}{c}\text { NPV } \\
(\%)\end{array}$ & $\begin{array}{c}\text { Accuracy } \\
(\%)\end{array}$ \\
\hline All LNs $(n=707)$ & 2.9 & 15.0 & 83.0 & 81.2 & 80.2 & 82.4 & 81.7 \\
Preoperative LNs $(n=295)$ & 2.9 & 15.3 & 87.5 & 83.4 & 69.4 & 94.0 & 84.7 \\
Preoperative LNs $(n=295)$ & 9.6 & 11.5 & 87.5 & 88.2 & 77.0 & 94.4 & 88.5 \\
Postoperative LNs $(n=412)$ & 2.9 & 14.8 & 95.0 & 86.9 & 77.2 & 87.6 & 89.0 \\
Postoperative LNs $(n=412)$ & 2.1 & 13.3 & 96.0 & 90.4 & 78.1 & 98.4 & 91.8 \\
\hline
\end{tabular}

LNs: lymph nodes, NPV: negative predictive value, PPV: positive predictive value 
washout $\mathrm{Tg}-$ ), 15 were metastatic and four were benign in the final diagnosis. Among the $15 \mathrm{LNs}$ that were metastatic in the final diagnosis, two LNs in one patients (washout $\mathrm{Tg}$ of 0.05 and $0.15 \mathrm{ng} / \mathrm{dL}$ ) were poorly DTC with high TgAb titer $(1896.7 \mathrm{IU} / \mathrm{mL})$ and this patient underwent radiotherapy. One LN (washout Tg $0.02 \mathrm{ng} / \mathrm{dL}, \operatorname{TgAb} 7.73 \mathrm{IU} / \mathrm{mL}$ ) was finally diagnosed with anaplastic thyroid cancer (ATC). FNAC with washout Tg showed concordant results (FNAC-washout $\mathrm{Tg}-$ ) in 257 of $293(87.7 \%)$ benign LNs. Two postoperative LNs in one patient showed metastatic histology. The FNAC results in these two LNs presented as diffuse sclerosis combined with high $\mathrm{TgAb}$ $(157.21 \mathrm{IU} / \mathrm{mL})$. Finally, these $\mathrm{LNs}$ were proven to be metastatic PTC by histopathology. Among 36 LNs with FNAC - washout $\mathrm{Tg}+$, nine were finally proven to be metastatic LNs. Two of nine metastatic LNs in final diagnosis showed insufficient cellularity of cytology. Two LNs consisted of colloid in FNAC sample. Three LNs of nine metastatic LN showed negative cytology with only cystic fluid and diagnosed with metastatic PTC by repeat FNAC. Two LNs showed benignity with degenerated inflammatory cells in FNAC.

\section{Decision Making for Discordant LNs between FNAC and Washout Tg (Fig. 2)}

Among preoperative LNs, the majority of FNAC+ or washout $\mathrm{Tg}+\mathrm{LNs}$ was dissected with thyroidectomy. All 10 of FNAC+washout $\mathrm{Tg}-$ and 21 of 24 FNACwashout $\mathrm{Tg}+\mathrm{LN}$ were dissected (Fig. 2, right panels). Among 19 postoperative FNAC+washout $\mathrm{Tg}-\mathrm{LNs}$, three LNs were not managed with any other diagnostic or therapeutic methods such as dissection, radioiodine ablation (RAI), or repeat FNAC; Two cystic metastases in FNAC were diminished after FNAC and not detected in follow-up imaging studies. One LN showed atypia in FNAC but was not detected in neck CT and follow-up thyroid US during study period. Three of 19 postoperative FNAC + washout $\mathrm{Tg}-\mathrm{LNs}$ received RAI. 25 of 36 FNAC - washout $\mathrm{Tg}+$ postoperative $\mathrm{LNs}$ were dissected (Fig. 2, rightmost panels). Five FNACwashout $\mathrm{Tg}+$ were not dissected and decreased in size in follow-up imaging during the study period. Six of 36 LNs had repeated FNAC; four LNs were benign and two were metastatic.

Overall, 8.9\% (63 of 707) of LN findings were not in agreement between FNAC with washout $\mathrm{Tg}$ and the final LN diagnosis or were inconclusive results from FNAC with washout Tg. In postoperative LNs, discrepancies were less frequent compared to those in preoperative LNs. Inconclusive results were observed in 9.2\% (27/295) of preoperative LNs and $8.7 \%(36 / 412)$ of postoperative LNs. $12.8 \%$ preoperative LNs (17/132 dissected LNs) and $15.0 \%$ of postoperative LNs

\begin{tabular}{|c|c|c|c|}
\hline \multicolumn{2}{|c|}{ Preoperative LNs } & \multicolumn{2}{|c|}{ Postopeative LNs } \\
\hline $\begin{array}{l}\text { FNAC+washout Tg- } \\
(n=10)\end{array}$ & $\begin{array}{l}\text { FNAC-washout } \mathrm{Tg}^{+} \\
(\mathrm{n}=24)\end{array}$ & $\begin{array}{l}\text { FNAC+washout Tg- } \\
(n=19)\end{array}$ & $\begin{array}{l}\text { FNAC-washout } \mathrm{Tg}^{+} \\
(\mathrm{n}=36)\end{array}$ \\
\hline $\begin{array}{c}\text { Initial decision } \\
\text { LNs dissection }(n=10)\end{array}$ & $\begin{array}{c}\text { Initial decision } \\
\text { LNs dissection }(n=21) \\
\text { No dissection }(n=3)\end{array}$ & $\begin{array}{c}\text { Initial decision } \\
\text { LNs dissection }(n=11) \\
\text { No dissection }(n=3) \\
\text { RAI }(n=3) \\
\text { Repeat FNAC }(n=2)\end{array}$ & $\begin{array}{c}\text { Initial decision } \\
\text { LNs dissection }(n=25) \\
\text { No dissection }(n=5) \\
\text { Repeat FNAC }(n=6)\end{array}$ \\
\hline $\begin{array}{l}\text { Final diagnosis of } 10 \\
\text { dissected LNs: } \\
\text { Metastatic }(n=7) \\
\text { Benign }(n=3)\end{array}$ & $\begin{array}{l}\text { Final diagnosis of } 21 \\
\text { dissected LNs: } \\
\text { Metastatic }(n=7) \\
\text { Benign }(n=14) \\
\text { No LNs dissection: } \\
\text { Benign }(n=3)\end{array}$ & $\begin{array}{l}\text { Final diagnosis of } 11 \\
\text { dissected LNs: } \\
\text { Metastatic }(n=10) \\
\text { Benign }(n=1) \\
\text { No LNs dissection with } \\
\text { image follow up: } \\
\text { Benign }(n=3) \\
\text { RAl: } \\
\text { Metastatic }(n=3) \\
\text { Repeat FNAC: } \\
\text { Metastatic }(n=2)\end{array}$ & $\begin{array}{l}\text { Final diagnosis of } 25 \\
\text { dissected LNs: } \\
\text { Metastatic }(n=7) \\
\text { Benign }(n=18) \\
\\
\text { No LNs dissection with } \\
\text { image follow up: } \\
\text { Benign ( }=5) \\
\text { Repeat FNAC: } \\
\text { Metastatic }(n=2) \\
\text { Benign }(n=4)\end{array}$ \\
\hline
\end{tabular}

Fig. 2. Decision making in discordant LNs between FNAC combined with washout $\mathrm{Tg}$ 
(19/127 dissected LNs) were performed unnecessary dissection due to false positive of washout $\mathrm{Tg}$ and false positivity in FNAC. To confirm diagnosis, there are needed repeat invasive FNAC, image study including neck $\mathrm{CT}$, and PET-CT.

\section{Discussion}

Washout Tg measurement in FNA has been suggested as a supplementary diagnostic tool to FNAC since it was first performed by Pacini et al. ${ }^{8)}$ in 1992. Although the diagnostic performance has been improved with combined diagnostic modalities, ${ }^{21)}$ diagnostic cut-off values of washout Tg have not been established, and there are discrepancies between FNAC and washout $\mathrm{Tg}$ levels due to a wide range of washout Tg cut-off values and cytological insufficiency. To our knowledge, no study has evaluated the discordant rates of FNAC and washout Tg levels in both preoperative and postoperative settings simultaneously and in real-world practice.

In this study, discordant or inconclusive results occurred in any LNs for FNAC with atypia or cystic metastasis. four of $78 \mathrm{LNs}$ with FNAC + washout $\mathrm{Tg}+$ had benignity in final $L N$ diagnosis. These four benign LN in histopathology presented AUS and metastatic PTC in FNAC before thyroidectomy. Three LNs from 10 preoperative $\mathrm{FNAC}+$ washout $T g$ - LNs were benign result of histopathology. There were no metastatic LN among all dissected LN in same compartment and at the biopsy location. It is worth mentioning that tissue from near intact thyroid lesion during FNAC before surgery would be obtained. Cystic transformation could be another challenge to diagnosis for metastatic LNs and was reported in primary DTC and in metastatic $\mathrm{LNs}^{22)}$ In preoperative $24 \mathrm{LNs}$ with FNACwashout $\mathrm{Tg}+$ and postoperative $36 \mathrm{LNs}$ with FNACwashout $\mathrm{Tg}+$, some of these LNs were metastatic on final diagnosis and they presented cystic change on thyroid US. Cystic changes in metastatic LNs are a diagnostic challenge and may show false negative results because of their low cellularity. ${ }^{23)}$ Hatabu et al. ${ }^{24)}$ reported that results of FNAC were metastatic in only $33 \%$ LNs with cystic change. Therefore, close exami- nation for the detection of cystic LNs from DTC is needed. Majority of discordant cases between FNAC and final LN diagnosis came from inadequate or low cytology due to calcification or cystic portion.

In the present study, the optimal cut-off value for washout $\mathrm{Tg}$ in all LNs was $2.9 \mathrm{ng} / \mathrm{dL}$. The cut-off value for washout $\mathrm{Tg}(9.6 \mathrm{ng} / \mathrm{mL})$ for malignant diagnosis in the preoperative setting was higher than that for the postoperative setting $(2.1 \mathrm{ng} / \mathrm{mL})$. This result was consistent with previous studies. ${ }^{25,26)}$ Several studies have suggested a wide range of preoperative washout Tg levels, 0.2 to $39.3 \mathrm{ng} / \mathrm{dL}^{18,27)}$ To improve the $\mathrm{diag}-$ nostic performance of both FNAC and washout Tg, several centers use the washout $\mathrm{Tg} /$ serum $\mathrm{Tg}$ ratio to adjust the influence of serum $\mathrm{Tg}$ in preoperative LNs. ${ }^{7,12,28)}$ However, the diagnostic performance was not significantly higher than that for FNAC with washout $\mathrm{Tg}$ and serum $\mathrm{Tg}$ level did not differ significantly between metastatic and benign LNs, regardless of surgery. Therefore, we used FNAC with washout Tg for the evaluation of discrepant results. A previous study in our center on preoperative LNs with or without TgAb reported washout Tg cut-off values ranging from $2.5 \mathrm{ng}$ to $8.5 \mathrm{ng} / \mathrm{mL}$ according to TgAb positivity. ${ }^{15)}$ This difference may be due to the different study period and lack of classification according to TgAb titer in this study. In LNs awaiting thyroidectomy, a higher washout $\mathrm{Tg}$ cut-off value $(9.6 \mathrm{ng} / \mathrm{mL})$ showed high performance in sensitivity, PPV, NPV, and accuracy. Our washout Tg threshold for metastatic LNs was higher than those of previous studies (0.6$1.1 \mathrm{ng} / \mathrm{mL})^{28,29)}$ However, these previous studies were not based on a large number of LNs but based on only small case series. Moreover, higher cut-off values to $2.1 \mathrm{ng} / \mathrm{mL}$ and $9.6 \mathrm{ng} / \mathrm{mL}$ showed good diagnostic performance without decreasing sensitivity.

Our study has several strengths. First, the large-scale patient samples included real-world data. Secondly, all patients included in this study had a complete biochemical data for serum $\mathrm{Tg}$ and $\mathrm{TgAb}$ levels. Thirdly, we used different cut-off values for washout $\mathrm{Tg}$ according to surgery status. Therefore, the diagnostic performance was better than that in other studies. 
This study also has several limitations. The retrospective study design might have led to selection bias in the interpretation of the results. Second, we included LNs without dissection, the final outcomes of which were decided only by follow-up imaging.

Washout Tg measurement in FNA washout is useful with, good diagnostic performance and no need for additional invasive procedures. However, false positive or false negative findings are not infrequent with FNAC in real-world clinical conditions and there is a need for accurate diagnostic tools in real-world practice.

In real-world practice, discordant results between FNAC with washout Tg and final LN outcomes may occur in up to $10 \%$ of cases, which can lead to unnecessary neck dissection or additive procedures. To improve the diagnostic accuracy of FNAC with washout $\mathrm{Tg}$, washout $\mathrm{Tg}$ cut-off values should be applied depending on preoperative or postoperative LN status. Further research to identify new biomarkers in washout fluid is necessary to resolve discordant findings.

\section{Acknowledgments}

This study was presented in abstract form at 7th Seoul International Congress of Endocrinology and Metabolism's 2019 meeting in Seoul, South Korea.

\section{Conflicts of Interest}

No potential conflict of interest relevant to this article was reported.

\section{Orcid}

Jeongmin Lee: https://orcid.org/0000-0001-9074-8087 Hye Lim Park: https://orcid.org/0000-0003-1089-6261 Kwanhoon Jo: https://orcid.org/0000-0003-3308-6560 Min-Hee Kim: https://orcid.org/0000-0002-7506-5912 Ja Seong Bae: https://orcid.org/0000-0002-6271-2105 Sohee Lee: https://orcid.org/0000-0003-1559-8853 Chan Kwon Jung: https://orcid.org/0000-0001-6843-3708 So-Lyung Jung: https://orcid.org/0000-0002-3267-8399 Dong-Jun Lim: https://orcid.org/0000-0003-0995-6482

\section{References}

1) DeSantis CE, Miller KD, Goding Sauer A, Jemal A, Siegel RL. Cancer statistics for African Americans, 2019. CA Cancer J Clin 2019;69(3):211-33.

2) Sakorafas GH, Sampanis D, Safioleas M. Cervical lymph node dissection in papillary thyroid cancer: current trends, persisting controversies, and unclarified uncertainties. Surg Oncol 2010; 19(2):e57-70.

3) Sherman SI, Perrier N, Clayman GL. 60 years of survival outcomes at the University of Texas MD Anderson Cancer Center. In: Thyroid cancer. New York: Springer New York; 2013. p.295-310.

4) Wang LY, Palmer FL, Nixon IJ, Thomas D, Shah JP, Patel $\mathrm{SG}$, et al. Central lymph node characteristics predictive of outcome in patients with differentiated thyroid cancer. Thyroid 2014;24(12):1790-5.

5) Conzo G, Pasquali D, Bellastella G, Esposito K, Carella C, De Bellis A, et al. Total thyroidectomy, without prophylactic central lymph node dissection, in the treatment of differentiated thyroid cancer. Clinical retrospective study on 221 cases. Endocrine 2013;44(2):419-25.

6) Haugen BR, Alexander EK, Bible KC, Doherty GM, Mandel SJ, Nikiforov YE, et al. 2015 American Thyroid Association management guidelines for adult patients with thyroid nodules and differentiated thyroid cancer: the American Thyroid Association guidelines task force on thyroid nodules and differentiated thyroid cancer. Thyroid 2016;26(1):1-133.

7) Aydin C, Ozdemir D, Sacikara M, Polat SB, Yazgan AK, Turkolmez S, et al. A new approach for standardization and increased accuracy of lymph node washout thyroglobulin in patients with differentiated thyroid carcinoma. Diagn Cytopathol 2016;44(3):177-86.

8) Pacini F, Fugazzola L, Lippi F, Ceccarelli C, Centoni R, Miccoli P, et al. Detection of thyroglobulin in fine needle aspirates of nonthyroidal neck masses: a clue to the diagnosis of metastatic differentiated thyroid cancer. J Clin Endocrinol Metab 1992;74(6):1401-4.

9) Leenhardt L, Erdogan MF, Hegedus L, Mandel SJ, Paschke R, Rago T, et al. 2013 European Thyroid Association guidelines for cervical ultrasound scan and ultrasound-guided techniques in the postoperative management of patients with thyroid cancer. Eur Thyroid J 2013;2(3):147-59.

10) Giovanella L, Ceriani L, Suriano S, Crippa S. Thyroglobulin measurement on fine-needle washout fluids: influence of sample collection methods. Diagn Cytopathol 2009;37(1):42-4.

11) Cignarelli M, Ambrosi A, Marino A, Lamacchia O, Campo M, Picca G, et al. Diagnostic utility of thyroglobulin detection in fine-needle aspiration of cervical cystic metastatic lymph nodes from papillary thyroid cancer with negative cytology. Thyroid 2003;13(12):1163-7.

12) Uruno T, Miyauchi A, Shimizu K, Tomoda C, Takamura $\mathrm{Y}$, Ito $\mathrm{Y}$, et al. Usefulness of thyroglobulin measurement in fine-needle aspiration biopsy specimens for diagnosing cervical lymph node metastasis in patients with papillary thyroid cancer. 
World J Surg 2005;29(4):483-5.

13) Cunha N, Rodrigues F, Curado F, Ilheu O, Cruz C, Naidenov $\mathrm{P}$, et al. Thyroglobulin detection in fine-needle aspirates of cervical lymph nodes: a technique for the diagnosis of metastatic differentiated thyroid cancer. Eur J Endocrinol 2007;157(1):101-7.

14) Boi F, Baghino G, Atzeni F, Lai ML, Faa G, Mariotti S. The diagnostic value for differentiated thyroid carcinoma metastases of thyroglobulin (Tg) measurement in washout fluid from fine-needle aspiration biopsy of neck lymph nodes is maintained in the presence of circulating anti-Tg antibodies. J Clin Endocrinol Metab 2006;91(4):1364-9.

15) Jo K, Kim MH, Lim Y, Jung SL, Bae JS, Jung CK, et al. Lowered cutoff of lymph node fine-needle aspiration thyroglobulin in thyroid cancer patients with serum anti-thyroglobulin antibody. Eur J Endocrinol 2015;173(4):489-97.

16) Shin JH, Baek JH, Chung J, Ha EJ, Kim JH, Lee YH, et al. Ultrasonography diagnosis and imaging-based management of thyroid nodules: revised Korean Society of Thyroid Radiology consensus statement and recommendations. Korean J Radiol 2016;17(3):370-95.

17) Jung CK, Hong S, Bychkov A, Kakudo K. The use of fine-needle aspiration (FNA) cytology in patients with thyroid nodules in Asia: a brief overview of studies from the working group of Asian Thyroid FNA cytology. J Pathol Transl Med 2017;51(6):571-8.

18) Kim MJ, Kim EK, Kim BM, Kwak JY, Lee EJ, Park CS, et al. Thyroglobulin measurement in fine-needle aspirate washouts: the criteria for neck node dissection for patients with thyroid cancer. Clin Endocrinol (Oxf) 2009;70(1):145-51.

19) Sohn YM, Kim MJ, Kim EK, Kwak JY. Diagnostic performance of thyroglobulin value in indeterminate range in fine needle aspiration washout fluid from lymph nodes of thyroid cancer. Yonsei Med J 2012;53(1):126-31.

20) Jeon MJ, Park JW, Han JM, Yim JH, Song DE, Gong G, et al. Serum antithyroglobulin antibodies interfere with thyroglobulin detection in fine-needle aspirates of metastatic neck nodes in papillary thyroid carcinoma. J Clin Endocrinol Metab 2013; 98(1):153-60.
21) Grani G, Fumarola A. Thyroglobulin in lymph node fine-needle aspiration washout: a systematic review and meta-analysis of diagnostic accuracy. J Clin Endocrinol Metab 2014;99(6): 1970-82.

22) Clark A, Manduch M, Hollins R, Awad S. Metastatic papillary thyroid cancer presenting with a recurrent necrotic cystic cervical lymph node. Endocrinol Diabetes Metab Case Rep 2019;2019(1): 18-0105.

23) Landry CS, Grubbs EG, Busaidy NL, Monroe BJ, Staerkel GA, Perrier ND, et al. Cystic lymph nodes in the lateral neck as indicators of metastatic papillary thyroid cancer. Endocr Pract 2011;17(2):240-4.

24) Hatabu H, Kasagi K, Yamamoto K, Iida $Y$, Misaki T, Hidaka $\mathrm{A}$, et al. Cystic papillary carcinoma of the thyroid gland: a new sonographic sign. Clin Radiol 1991;43(2):121-4.

25) Bruno R, Giannasio P, Chiarella R, Capula C, Russo D, Filetti S, et al. Identification of a neck lump as a lymph node metastasis from an occult contralateral papillary microcarcinoma of the thyroid: key role of thyroglobulin assay in the fine-needle aspirate. Thyroid 2009;19(5):531-3.

26) Giovanella L, Ceriani L, Suriano S. Lymph node thyroglobulin measurement in diagnosis of neck metastases of differentiated thyroid carcinoma. J Thyroid Res 2011;2011:621839.

27) Borel AL, Boizel R, Faure P, Barbe G, Boutonnat J, Sturm $\mathrm{N}$, et al. Significance of low levels of thyroglobulin in fine needle aspirates from cervical lymph nodes of patients with a history of differentiated thyroid cancer. Eur J Endocrinol 2008; 158(5):691-8.

28) Snozek CL, Chambers EP, Reading CC, Sebo TJ, Sistrunk JW, Singh RJ, et al. Serum thyroglobulin, high-resolution ultrasound, and lymph node thyroglobulin in diagnosis of differentiated thyroid carcinoma nodal metastases. J Clin Endocrinol Metab 2007;92(11):4278-81.

29) Smallridge RC, Meek SE, Morgan MA, Gates GS, Fox TP, Grebe $\mathrm{S}$, et al. Monitoring thyroglobulin in a sensitive immunoassay has comparable sensitivity to recombinant human tsh-stimulated thyroglobulin in follow-up of thyroid cancer patients. J Clin Endocrinol Metab 2007;92(1):82-7. 